\title{
Influence of Stator Configuration on High Frequency Signal Injection Based Permanent Magnet Temperature Estimation Methods in PMSMs
}

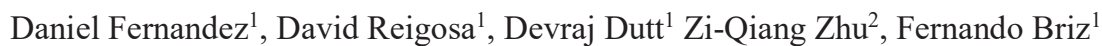 \\ ${ }^{1}$ University of Oviedo. Dept. of Elect., Computer \& System $\quad{ }^{2}$ University of Sheffield. Department of Electronic and \\ Engineering, Gijón, 33204, Spain. \\ Electrical Engineering, UK. \\ fernandezalodaniel@uniovi.es, diazdavid@uniovi.es, devraj.dutt@gmail.com, z.q.zhu@sheffield.ac.uk, fernando@isa.uniovi.es
}

\begin{abstract}
The performance and life expectance of Permanent Magnet Synchronous Machines (PMSMs) is strongly affected by the PM temperature. An increase of the PM temperature reduces the PM strength and consequently the machine torque production capability. Also there is a risk of irreversible demagnetization if PM temperature is too high. Directly measurement of the PM temperature is not easy, PM temperature estimation methods have therefor been widely investigated during the last decade. PM temperature estimation methods can be divided into thermal models, BEMF methods and methods based on the injection of some type of test signal in the stator terminals of the machine. Thermal models require previous knowledge of the machine geometry, materials and cooling system. BEMF and high frequency signal injection methods do not require previous knowledge of the machine geometry or cooling system. However, BEMF methods require that the machine is rotating. High frequency signal injection methods can be used at any speed, including standstill. However, there is a number of issues that can affect to the accuracy of these methods, including stator and rotor designs, machine assembling tolerances and rotor lamination grain orientation. This paper analyzes the sensitivity of high frequency signal based temperature estimation methods to the stator design. ${ }^{1}$
\end{abstract}

Index Terms - high frequency signal injection, magnet temperature estimation, permanent magnet synchronous machines, stator configuration.

\section{INTRODUCTION}

$\mathrm{P}$ MSMs have been increasingly used in multiple applications, from domestic/household to aerospace, due to their high torque density, high efficiency and good dynamic performance. PMSM performance strongly depends on the PM temperature [1-2]. An increase of the PM temperature will reduce the magnet strength and consequently the machine torque production capability [1-2]. In addition, if the PM temperature becomes too high, PMs can be irreversibly demagnetized (locally or globally) [1-3]. These issues have raised the interest in the development of PM temperature measurement/estimation methods.

PM temperature measurement can be done using contact type (e.g. thermocouples) [4] and non-contact (e.g. infrared) type sensors [5]. Contact type sensors require the use of slip rings and brushes or alternatively some kind of wireless

1 This work was supported in part by Spanish Ministry of Education, Culture and Sports through "José Castillejo Program" under grant PX15/00354 and by Regional Ministry of Education, Culture and Sport of the Principality of Asturias through "Severo Ochoa Program" under Grant BP13067. transmission system [6]. On the other hand, non-contact sensors are relatively expensive and require the magnet surface to be visible [5]. Due to this, PM temperature measurement is not practical in commercial machines due to cost and/or robustness issues. An alternative to direct temperature measurement is the temperature estimation. PM temperature estimation methods can be divided into thermal model based methods [7-8], BEMF based methods [9-10] and methods based on the injection of some type of test signal in the stator terminals of the machine [4-5, 11-13].

Thermal models use a thermal network that models the heat transfer characteristics of the different machine parts. Knowledge of the machine geometry, materials and cooling system is therefore needed [7-8], calibration for each machine being required. This limitation is overcome by BEMF and signal injection methods. BEMF based methods estimate the magnet temperature from the estimated PM flux linkage [9]. While these methods provide accurate temperature estimation at mid-high speeds, their use is not viable at standstill or low speeds due to the reduced magnitude of the BEMF. nt he other hand, methods based on the injection of a test signal, can be divided into pulse injection based methods [12] and high frequency signal injection methods [4-5,11]. Pulse injection based methods typically inject a voltage pulse in the d-axis, the resulting current depending on the magnetization level, which is a function of the PM temperature. High frequency signal injection methods use the dependency of the stator reflected magnet resistance with the PM temperature. These methods can be used on the whole speed range of the machine, including zero speed. However, they require injection of an additional signal, which can have some adverse effects on the operation of the machine, e.g. extra losses, noise and vibration.

One potential concern for high frequency signal injection based methods is their sensitivity to constructive aspects, e.g. stator and rotor designs, slots/pole combination, magnet shape and volume, assembling tolerances (e.g. static eccentricities, dynamic eccentricities, mixed eccentricities, magnet assembling tolerances...), stator/rotor lamination grain orientation, sensitivity to rotor eccentricities, PM assembling tolerances and lamination grain orientation has been already analyzed [14].

This paper analyzes the sensitivity of high frequency signal injection based temperature estimation methods to the stator configuration and slot/pole $(\mathrm{s} / \mathrm{p})$ combination. Preliminary results show that these issues can have a relevant impact on the performance of high frequency signal injection based methods, 
meaning that certain slots/pole combinations or stator winding configurations might be preferred.

This paper is organized as follows: magnet temperature estimation using a high frequency signal is briefly reviewed in section II. Effects of the stator and rotor configuration on the estimated PM temperature are analyzed in section III, FEA results are shown in section IV and conclusions are summarized in section $\mathrm{V}$.

\section{Magnet Temperature Estimation Using A High FREQUENCY SIGNAL INJECTION}

This section briefly reviews the physical principles of magnet temperature estimation using a high frequency signal. The high frequency model of a PMSM expressed in the synchronous rotor reference frame is described by (1) [4], where $v_{d q h f}^{r}$ and $i_{d q h f}^{r}$ are the stator voltage and current complex vectors in the rotor synchronous reference frame, $R_{d h f}^{r}, R_{q h f}^{r}, L_{d h f}^{r}$ and $L_{d h f}^{r}$ are the $d$ and $q$-axis resistances and inductances respectively, $\omega_{r}$ is the machine speed, and $p$ is the differential operator.

$$
\begin{aligned}
& {\left[\begin{array}{c}
v_{d h f}^{r} \\
v_{q h f}^{r}
\end{array}\right]=\left[\begin{array}{ll}
R_{d h f} & 0 \\
0 & R_{q h f}
\end{array}\right]\left[\begin{array}{l}
i_{d h f}^{r} \\
i_{q h f}^{r}
\end{array}\right]+p\left[\begin{array}{ll}
L_{d h f} & 0 \\
0 & L_{q h f}
\end{array}\right]\left[\begin{array}{l}
i_{d h f}^{r} \\
i_{q h f}^{r}
\end{array}\right]} \\
& +\left[\begin{array}{cc}
0 & -\omega_{r} L_{q h f} \\
\omega_{r} L_{d h f} & 0
\end{array}\right]\left[\begin{array}{l}
i_{d h f}^{r} \\
i_{q h f}^{r}
\end{array}\right]
\end{aligned}
$$

Both $d$ and $q$-axis components of the high frequency resistances $R_{d h f}$ and $R_{q h f}$ are function of the stator and rotor high frequency resistances (2), where $R_{h f}$ ( $d$ or $q$-axis) is the high frequency resistance seen from the stator terminals, $R_{s h f}$ is the contribution of the stator circuit to the high frequency resistance and $R_{r h f}$ is the stator-reflected rotor high frequency resistance.

$$
R_{h f}=R_{\text {shf }}+R_{r h f}
$$

Stator and rotor high frequency resistances are a function of the corresponding stator and rotor temperatures as generically shown by (3), where $R\left(\mathrm{~T}_{0}\right)$ is the stator/rotor resistance at the room temperature [4]-[6], $\alpha=\alpha_{c u}$ for the case of the stator high frequency resistance, i.e. copper thermal resistive coefficient, and $\alpha=\alpha_{\text {mag }}$ for the case of rotor high frequency resistance, i.e. magnet thermal resistive coefficient.

$$
R(T)=R\left(T_{0}\right)(1+\alpha \Delta T)
$$

It was shown in [5] that the magnet temperature can be estimated from the stator-reflected PM high frequency resistance variation with temperature. Different forms of high frequency excitation have been proposed for this purpose, rotating high frequency voltage and $d$-axis pulsating high frequency current being the most popular options. Both are briefly described following.

\section{A. Rotating high frequency signal}

When a rotating high frequency voltage (4) is applied to the stator windings of a PMSM, the induced stator $q$ - and $d$-axis high frequency currents are given by (5) and (6) respectively. Obtaining $R_{d h f}$ and $R_{q h f}$ from (5)-(6) is not trivial due to the cross-coupling that exists between the $d$ and $q$-axes and to the dependence on the machine speed. Assumed that $\omega_{h f}>>\omega_{r}$, (5)-(6) can be simplified to (7)-(8). While such assumption can be realistic in SPMSMs, its extension to IPMSMs is arguable. In this case, $R_{d h f},(10)$,can be obtained from the real part of the $d$-axis high frequency impedance (9). $R_{d h f}$ can be written as a function of the stator and rotor temperatures $T_{s}$ and $T_{r}$ (10), the magnet temperature $T_{r}$ being obtained using (11).

$$
\begin{aligned}
& v_{d q h f}^{r^{*}}=V_{h f} e^{j\left(\omega_{h f t} t\right)} \\
& i_{d h f}^{r}=\left[v_{d h f}^{r *}+\frac{\omega_{r} L_{q h f} v_{q h f}^{r}}{R_{q h f}+j \omega_{h f} L_{q h f}}\right] \\
& \frac{R_{q h f}+j \omega_{h f} L_{q h f}}{\left(R_{d h f}+j \omega_{h f} L_{d h f}\right)\left(R_{q h f}+j \omega_{h f} L_{q h f}\right)+\omega_{r}^{2} L_{d h f} L_{q h f}} \\
& i_{q h f}^{r}=\frac{v_{q h f}^{r *}-\omega_{r} L_{d h f} i_{d h f}^{r}}{R_{q h f}+j \omega_{h f} L_{q h f}} \\
& i_{d h f}^{r}=\frac{v_{d h f}^{r *}}{R_{d h f}+j \omega_{h f} L_{d h f}} \\
& i_{q h f}^{r}=\frac{v_{q h f}^{r *}}{R_{q h f}+j \omega_{h f} L_{q h f}} \\
& Z_{d}=R_{d h f}+j \omega_{h f} L_{d h f}=\frac{v_{d h f}^{r *}}{i_{d h f}^{r}} \\
& R_{d h f}=R_{d h f\left(T_{s}, T_{r}\right)}=R_{d s h f\left(T_{s}\right)}+R_{d r h f\left(T_{r}\right)} \\
& T_{r}=\frac{R_{d h f\left(T_{s}, T_{r}\right)}-R_{d s h f\left(T_{0}\right)}\left(1+\alpha_{c u}\left(T_{s}-T_{0}\right)\right)-R_{d r h f\left(T_{0}\right)}}{R_{d r h f\left(T_{0}\right)} \alpha_{m a g}}+T_{0}
\end{aligned}
$$

\section{B. D-axis pulsating high frequency current}

If a sinusoidal high frequency current is injected in the $d$-axis of a PMSM (12), a voltage complex vector composed only by the induced $d$-axis voltage could be defined as (13). Both (12) and (13) can be decomposed into positive sequence $\left(i_{d q h f p c}^{r^{\prime}}\right.$ and $\left.v_{d q h f p c}^{r^{\prime}}\right)$ and negative sequence $\left(i_{d q h f n c}^{r^{\prime}}\right.$ and $\left.n_{d q h f n c}^{r^{\prime}}\right)$ components. The $d$-axis impedance (14) can be obtained from (12) and (13) using either the positive or the negative sequence component, where $\varphi_{Z d},(15)$, is the phase of the $d$-axis PMSM impedance. $R_{d h f}$ is obtained from the real part of the $d$-axis high frequency impedance (16), the magnet temperature, $T_{r}$, being eventually obtained using (11).

$$
\begin{aligned}
& i_{d q h f}^{r^{*}}=\left[\begin{array}{c}
\bar{i}_{d h f}^{r^{*}} \\
\bar{i}_{q h f}^{r^{*}}
\end{array}\right]=\left[\begin{array}{c}
I_{h f}^{*} \cos \left(\omega_{h f} t\right) \\
0
\end{array}\right] \\
& =\frac{I_{h f}}{2} e^{j \omega_{h f} t}+\frac{I_{h f}}{2} e^{-j \omega_{h f} t}=i_{d q h f p c}^{r *}+i_{d q h f n c}^{r *} \\
& V_{d q h f}^{r^{\prime}}=\left[\begin{array}{c}
\left(R_{d h f}+j \omega_{h f} L_{d h f}\right) \bar{i}_{d h f}^{r^{*}} \\
0
\end{array}\right]=\left[\begin{array}{c}
V_{d q h f}^{r^{\prime}} \cos \left(\omega_{h f} t+\varphi_{z d}\right) \\
0
\end{array}\right] \\
& =\frac{\left|v_{d q h f}^{r^{\prime}}\right|}{2} e^{j\left(\omega_{h f} t-\varphi_{Z d}\right)}+\frac{\left|v_{d q h f}^{r^{\prime}}\right|}{2} e^{j\left(-\omega_{h f} t+\varphi_{Z d}\right)}=v_{d q h f p c}^{r^{\prime}}+v_{d q h f n c}^{r^{\prime}}
\end{aligned}
$$




$$
\begin{aligned}
& Z_{d}=R_{d h f}+j \omega_{h f} L_{d h f}=\frac{v_{d q h f p c}^{r^{\prime}}}{i_{d q h f p c}^{r^{*}}}=\frac{v_{d q h f n c}^{r^{\prime}}}{i_{d q h f n c}^{r^{*}}} \\
& \varphi_{Z d}=\tan ^{-1}\left(\frac{\omega_{h f} L_{d h f}}{R_{d h f}}\right) \\
& R_{d h f}=Z_{d} \cos \left(\varphi_{Z d}\right) \\
& \frac{\partial R_{d r h f\left(T_{r}\right)}}{\partial T_{r}}=\alpha_{m a g}
\end{aligned}
$$

\section{EFFECTS OF STATOR AND ROTOR CONFIGURATION ON THE ESTIMATED PM TEMPERATURE}

The sensitivity of temperature estimation using high frequency signal injection to constructive parts of the rotor such as rotor eccentricities, lamination grain orientation and PM assembling tolerances, have already been studied [14]. It has been shown that static, dynamic and mixed eccentricities have an important impact on the estimated high frequency resistance. The lamination grain orientation can also compromise the accuracy of the method, whereas PM assembling tolerances has a negligible impact over the estimated magnet temperature [14].

This section analyzes the influence of the stator design and slot/pole combination on the sensitivity of high frequency signal injection based temperature estimation methods. Most common stator configurations and slots/pole combinations in traction and general purpose applications will be analyzed. For the analysis being presented in this this section, all machines designs will have the same dimensions and rated power. The objective of this analysis is to provide guidelines for the design of PMSM suitable for the implementation of high frequency signal based temperature estimation techniques.

Fig. 1 shows the four rotor topologies that will be considered, with $6,8,10$ and 16 pole. For each rotor design, distributed winding with different coil pitch and concentrated winding configurations will be evaluated. Table I summarizes the designs being considered. Stator and rotor lamination materials and magnet material are the same in all the cases. The distance between the center of the magnet and the gap is also kept constant, meaning that the reluctance paths are similar for all designs. Magnet thickness is also the same for all models, skin effect being therefor similar [18]. Magnet volume also remains invariant.

Table II shows the main characteristics of all machines designs including $\mathrm{d}$ and $\mathrm{q}$-axis inductances, average gap flux density, number of turn, voltage constant and torque constant. It is noted that some of the machines included in Table II with low coil pitch (i.e. 18/6(1), 36/6(1), 36/6(2), 60/10(1), $60 / 10(2) \ldots)$ might not be viable in practice due to their low efficiency. Nevertheless, they have been included for the sake of completeness of the analysis.

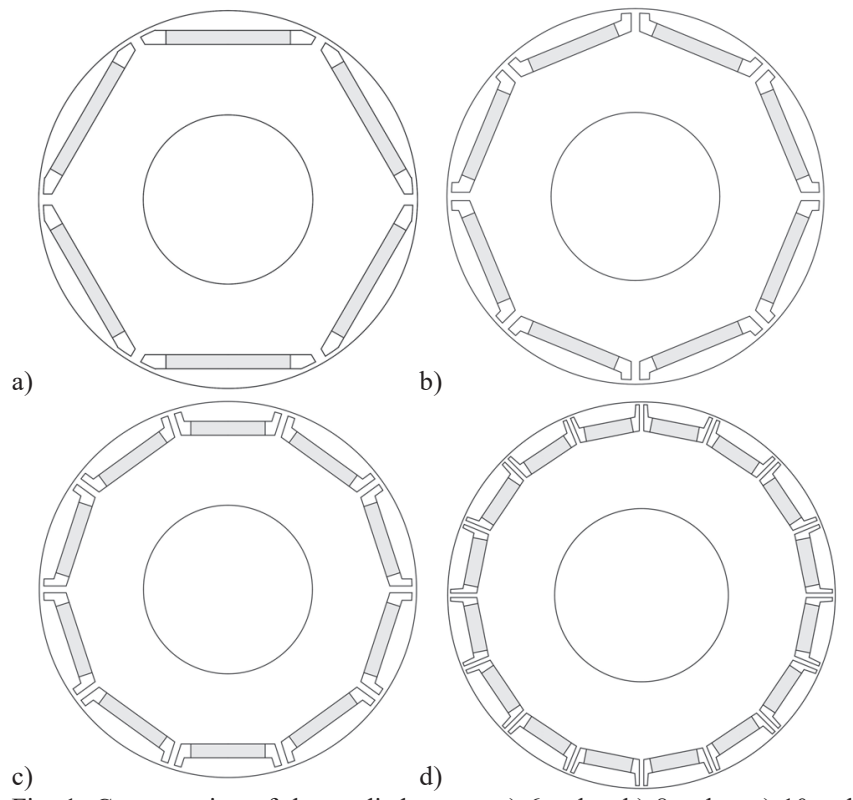

Fig. 1. Cross section of the studied rotors: a) 6 poles, b) 8 poles, c) 10 poles and d) 16 poles rotor.

\begin{tabular}{|c|c|c|c|c|c|c|}
\hline $\begin{array}{c}\text { Slot/pole } \\
\text { (coil } \\
\text { pitch) }\end{array}$ & $\mathrm{Ld}(\mathrm{mH})$ & $\mathrm{Lq}(\mathrm{mH})$ & $\mathrm{B}_{\text {gap }}(\mathrm{T})$ & $\mathrm{N}$ & $\mathrm{Kt}(\mathrm{Nm} / \mathrm{A})$ & $\mathrm{K}_{\mathrm{v}}(\mathrm{Vs} / \mathrm{rad})$ \\
\hline $9 / 6(1)$ & 28.9 & 24.5 & 0.649 & 149 & 1.313 & 1.506 \\
\hline $9 / 8(1)$ & 29.2 & 24.6 & 0.700 & 140 & 1.307 & 1.501 \\
\hline $12 / 8$ & 24.4 & 20.9 & 0.637 & 118 & 1.314 & 1.502 \\
\hline $9 / 10(1)$ & 33.6 & 27.8 & 0.678 & 150 & 1.312 & 1.518 \\
\hline $30 / 10(1)$ & 26.6 & 25.2 & 0.905 & 96 & 1.308 & 1.515 \\
\hline $24 / 16(1)$ & 22.4 & 18.2 & 0.557 & 79 & 1.309 & 1.509 \\
\hline $18 / 6(1)$ & 30.5 & 20.3 & 0.841 & 132 & 1.314 & 1.510 \\
\hline $18 / 6(2)$ & 20.3 & 20.7 & 0.650 & 66 & 1.307 & 1.508 \\
\hline $18 / 6(3)$ & 22.2 & 22.1 & 0.845 & 56 & 1.314 & 1.505 \\
\hline $36 / 6(1)$ & 32.7 & 27.3 & 0.857 & 128 & 1.305 & 1.508 \\
\hline $36 / 6(2)$ & 23.6 & 24.3 & 0.801 & 64 & 1.309 & 1.508 \\
\hline $36 / 6(3)$ & 21.0 & 22.3 & 0.824 & 43 & 1.316 & 1.522 \\
\hline $36 / 6(4)$ & 20.0 & 21.9 & 0.787 & 34 & 1.310 & 1.520 \\
\hline $36 / 6(5)$ & 19.4 & 21.4 & 0.848 & 30 & 1.315 & 1.519 \\
\hline $36 / 6(6)$ & 18.3 & 20.7 & 0.813 & 28 & 1.314 & 1.514 \\
\hline $48 / 8(1)$ & 28.1 & 23.2 & 0.788 & 109 & 1.307 & 1.509 \\
\hline $48 / 8(2)$ & 23.4 & 21.2 & 0.749 & 55 & 1.313 & 1.519 \\
\hline $48 / 8(3)$ & 20.7 & 19.4 & 0.756 & 36 & 1.308 & 1.495 \\
\hline $48 / 8(4)$ & 19.4 & 18.5 & 0.745 & 28 & 1.309 & 1.526 \\
\hline $48 / 8(5)$ & 17.4 & 17.7 & 0.783 & 24 & 1.316 & 1.504 \\
\hline $48 / 8(6)$ & 17.0 & 17.1 & 0.730 & 23 & 1.308 & 1.555 \\
\hline $60 / 10(1)$ & 27.1 & 24.6 & 0.868 & 94 & 1.312 & 1.500 \\
\hline $60 / 10(2)$ & 22.9 & 22.6 & 0.853 & 47 & 1.316 & 1.508 \\
\hline $60 / 10(3)$ & 21.0 & 20.7 & 0.814 & 31 & 1.308 & 1.496 \\
\hline $60 / 10(4)$ & 19.0 & 19.7 & 0.846 & 24 & 1.317 & 1.513 \\
\hline $60 / 10(5)$ & 17.9 & 18.9 & 0.845 & 21 & 1.309 & 1.523 \\
\hline $60 / 10(6)$ & 15.6 & 17.3 & 0.822 & 19 & 1.314 & 1.482 \\
\hline
\end{tabular}

TABLE I. MACHINE DIMENSIONS

\begin{tabular}{|l|l||l|l|}
\hline \multicolumn{2}{|c||}{ Dimensions } & Machine & Feasible Coil Pitch \\
\hline Outer Diameter (mm) & 112 & $9 / 6$ & 1 \\
\hline Rotor Diameter (mm) & 67 & $9 / 8$ & 1 \\
\hline Airgap (mm) & 0.5 & $12 / 8$ & 1 \\
\hline Stack length (mm) & 40 & $9 / 10$ & 1 \\
\hline Magnet Thickness (mm) & 2.5 & $30 / 10$ & 1 \\
\hline Magnet Volume (mm $\left.{ }^{2}\right)$ & 2200 & $24 / 16$ & 1 \\
\hline $\begin{array}{l}\text { Distance from the center } \\
\text { of the magnet to the rotor } \\
\text { surface (mm) }\end{array}$ & 27.5 & $18 / 6$ & $1,2,3$ \\
\hline & & $30 / 6$ & $1,2,3,4,5,6$ \\
\cline { 2 - 4 } & $48 / 8$ & $1,2,3,4,5,6$ \\
\hline
\end{tabular}

TABLE II. RATED MACHINE PARAMETERS 


\section{FEA RESULTS}

The effects of the stator configuration and stator/slot combination on the sensitivity of high frequency signal injection based temperature estimation methods are analyzed in this section. For the simulation results that are shown in this paper a magnitude of $1 \mathrm{~A}(0.05 \mathrm{pu})$ will be used for both rotating and pulsating injections, $20 \mathrm{~A}$ being the rated current of all machines. FEA will be used for this purpose. Although experimental results are not included in this paper due to the unaffordable fabrication cost for all configurations being evaluated, FEA has been demonstrated to provide accurate estimation [11].

Fig. 2 shows the FEA results for all configurations of the $36 / 6$ machine, see Table I. Fig. 2 shows the $d$-axis high frequency resistance vs. magnet temperature obtained using rotating and pulsating signal injection. Three different PM temperatures of 20,60 and $80{ }^{\circ} \mathrm{C}$, and two different frequencies for the injected high frequency signal are considered.

It is observed from Fig. 2 that the estimated high frequency resistance increases as both magnet temperature and frequency do. It is also observed that rotating high frequency excitation typically shows higher high frequency resistances compared to pulsating excitation. This is because pulsating vector rotates synchronously with the rotor, meaning that the induced field interacts always with the same part of the rotor, typically the center of the magnet. For all IPMSMs designs that have been evaluated, this corresponds to the maximum airgap, and therefore to the maximum reluctance path. On the contrary, rotating excitation excites the entire magnet surface, the reluctance being an average of the whole machine circumference.

Instead of representing the high frequency resistance as a function of the magnet temperature, it was found more insightful to represent the $d$-axis high frequency resistance at $20^{\circ} \mathrm{C}, R_{d h f}$, and the rate of variation of $R_{d h f}$ with the magnet temperature, i.e. $R_{d h f}$ sensitivity the magnet temperature (17).

Table IV summarizes the FEA results for all machine topologies in Table I. A color code is used to represent the goodness of each design. Dark green is used to represent the most favorable cases, i.e. highest sensitivity and lowest resistance at $20^{\circ} \mathrm{C}$, dark red is used for the least favorable cases, i.e. lowest sensitivity and highest resistance at $20^{\circ} \mathrm{C}$.

It observed from Table IV that $R_{d h f}$ sensitivity to the magnet temperature is not the same in all configurations. For the use of high frequency signal injection temperature estimation based techniques, the higher is the sensitivity of $R_{d h f}$ to the magnet temperature, the more adequate is the design. Moreover, low $R_{d h f}$ magnitude at $20^{\circ} \mathrm{C}$ would be the preferred cases, as $R_{d h f}$ is a reliable indicator of the magnet losses, i.e. $R_{d h f}$ is proportional to the magnet losses (machines with high sensitivity and low magnet losses would be preferred).

Among all analyzed topologies, fractional integer (36/6, $48 / 8$ and 60/10) and integer slot machines (18/6), are the most favorable cases as they show the highest sensitivity. Only for these slot/pole arrangements, every rotor pole matches the stator coil center as shown in Fig 3c-f.
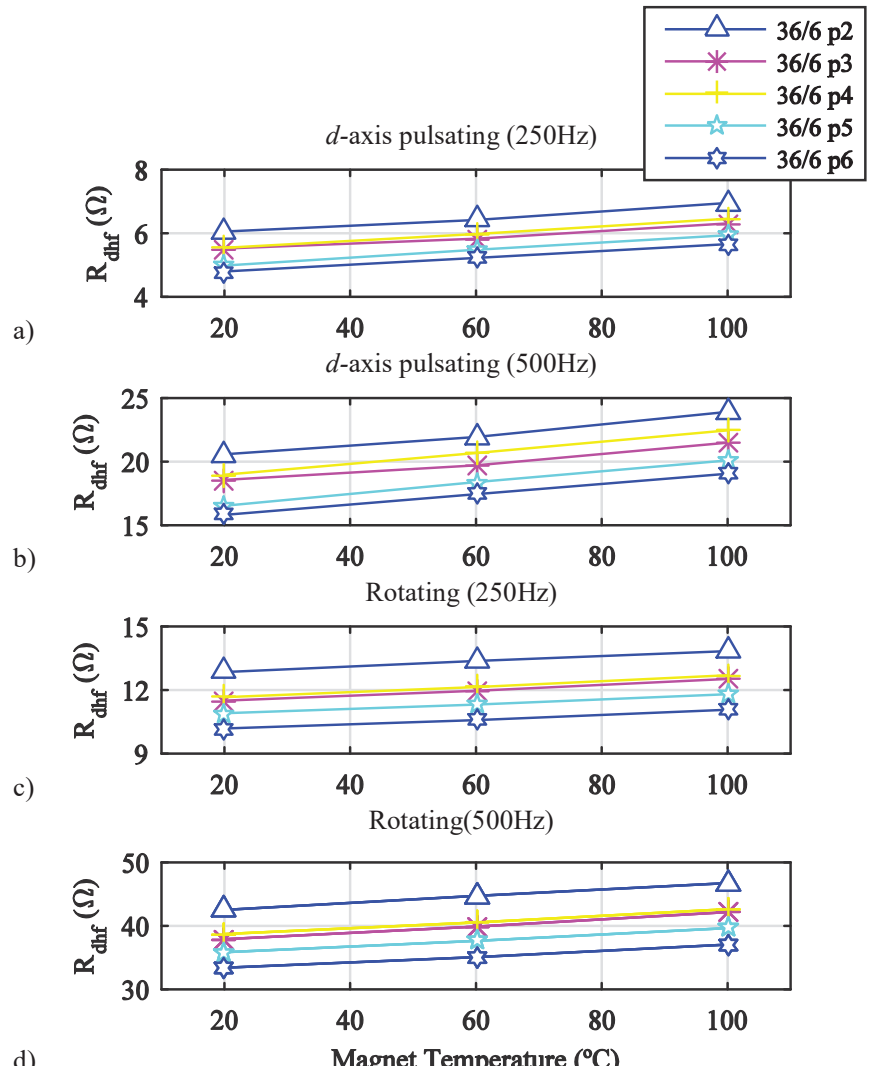

Fig. 2. Estimated high frequency resistance vs. magnet temperature of a $36 / 6$ machine for four different types of high frequency excitation, and for five different coil pitch. $I h f=1 \mathrm{~A}(0.05 \mathrm{pu}), I d q=0 \mathrm{~A}$

It can be also observed from Table IV for the pulsating injection that in all the cases the sensitivity decreases as the number of poles increases. This is because, as the total machine magnet volume is divided in a larger number of pieces, the equivalent electrical resistance seen from the stator is increased [18]. The same trends are observed for the rotating signal injection.

For concentrated winding machines, rotor magnets do not always match the stator coil center, the equivalent reluctance path being therefore higher than for the case of distributed winding machines. In addition, the injected signal does not excite uniformly the PMs in all the poles, which results in a lower sensitivity of the stator reflected magnet high frequency resistance to the magnet temperature variation (see Fig.3a and Fig.3b).

It can be also observed that for fractional slot winding machines, higher coil pitches present, in general, higher sensitivities. Arrangements with coil pitch of 5 and 6 for fractional slot machines uses the same number of stator slots to accommodate the coils of every phase. However, coil pitch 6 arrangement, encloses 6 teeth (i.e. the induced flux is driven through 6 teeth) while coil pitch 5, encloses only 5. When flux is driven through 5 teeth, the one in the center faces the magnet center, the rest of the teeth matching the rest of the 


\begin{tabular}{|c|c|c|c|c|c|c|c|c|c|c|c|c|c|c|c|c|}
\hline \multicolumn{17}{|c|}{ Table IV.HIGH FREQUENCY RESISTANCE AND SENSITIVITY } \\
\hline \multicolumn{17}{|c|}{ High frequency resistance calculated for $20^{\circ} \mathrm{C}$ magnet temperature, $\mathrm{R}_{\mathrm{hf}}(\Omega)$} \\
\hline \multicolumn{8}{|c|}{ Pulsating $d$-axis high frequency current $(0.05 \mathrm{pu})$} & \multicolumn{8}{|c|}{ Rotating high frequency current $(0.05 \mathrm{pu})$} & \multirow{2}{*}{$\mathrm{R}_{\mathrm{hf}}$ at $20^{\circ} \mathrm{C}$} \\
\hline $\mathrm{fhf}_{\mathrm{f}}(\mathrm{Hz})$ & $\mathrm{s} / \mathrm{p}$ & Pitch 6 & Pitch 5 & Pitch 4 & Pitch 3 & Pitch 2 & Pitch 1 & fhf(Hz) & $\mathrm{s} / \mathrm{p}$ & Pitch 6 & Pitch 5 & Pitch 4 & Pitch 3 & Pitch 2 & Pitch 1 & \\
\hline \multirow{10}{*}{250} & $9 / 6$ & & & & & & 8.934 & \multirow{10}{*}{250} & $9 / 6$ & & & & & & 10.932 & \multirow[t]{10}{*}{ Low } \\
\hline & $9 / 8$ & & & & & & 10.908 & & $9 / 8$ & & & & & & 11.421 & \\
\hline & $9 / 10$ & & & & & & 8.544 & & $9 / 10$ & & & & & & 10.692 & \\
\hline & $12 / 10$ & & & & & & 13.62 & & $12 / 10$ & & & & & & 13.325 & \\
\hline & $30 / 10$ & & & & & & 19.590 & & $30 / 10$ & & & & & & 23.435 & \\
\hline & $24 / 16$ & & & & & & 13.077 & & $24 / 16$ & & & & & & 14.070 & \\
\hline & $18 / 6$ & & & & 5.541 & 5.729 & 7.335 & & $18 / 6$ & & & & 10.791 & 11.162 & 14.727 & \\
\hline & $36 / 6$ & 4.796 & 4.988 & 5.546 & 5.567 & 6.051 & 7.595 & & $36 / 6$ & 10.191 & 10.912 & 11.665 & 11.501 & 12.856 & 18.102 & \\
\hline & $48 / 8$ & 6.211 & 6.041 & 7.076 & 8.923 & 14.340 & \begin{tabular}{|l|}
17.250 \\
\end{tabular} & & $48 / 8$ & 9.561 & 8.938 & 10.259 & 12.352 & 18.341 & 20.879 & \\
\hline & $60 / 10$ & 6.522 & 7.403 & 8.349 & 10.670 & 17.090 & 45.250 & & $60 / 10$ & 8.734 & \begin{tabular}{|l|}
9.862 \\
\end{tabular} & 10.951 & 13.578 & 20.378 & 48.508 & \\
\hline \multirow{10}{*}{500} & $9 / 6$ & & & & & & 32.162 & \multirow{10}{*}{500} & $9 / 6$ & & & & & & 40.807 & \multirow[t]{10}{*}{ Low } \\
\hline & $9 / 8$ & & & & & & 39.765 & & $9 / 8$ & & & & & & 42.181 & \\
\hline & $9 / 10$ & & & & & & 30.661 & & $9 / 10$ & & & & & & 39.655 & \\
\hline & $12 / 10$ & & & & & & 50.260 & & $12 / 10$ & & & & & & \begin{tabular}{|l|}
49.62 \\
\end{tabular} & \\
\hline & $30 / 10$ & & & & & & 45.81 & & $30 / 10$ & & & & & & 61.17 & \\
\hline & $24 / 16$ & & & & & & \begin{tabular}{|l|}
40.002 \\
\end{tabular} & & $24 / 16$ & & & & & & 44.31 & \\
\hline & $18 / 6$ & & & & 18.681 & 19.361 & 25.418 & & $18 / 6$ & & & & 35.350 & 36.670 & \begin{tabular}{|l|}
48.951 \\
\end{tabular} & \\
\hline & $36 / 6$ & 15.812 & 16.538 & 18.987 & 18.574 & 20.578 & 26.556 & & $36 / 6$ & 33.435 & 35.874 & 38.751 & 37.917 & 42.524 & \begin{tabular}{|l|}
50.226 \\
\end{tabular} & \\
\hline & $48 / 8$ & 18.122 & 17.474 & 19.897 & 23.087 & 30.987 & 41.179 & & $48 / 8$ & 30.86 & 29.01 & 32.632 & 36.780 & 47.031 & 55.921 & \\
\hline & $60 / 10$ & 19.131 & 21.32 & 23.309 & 27.270 & 36.200 & 74.58 & & $60 / 10$ & 27.589 & 31.125 & \begin{tabular}{|l|}
33.71 \\
\end{tabular} & 38.847 & 49.23 & \begin{tabular}{|l|}
87.65 \\
\end{tabular} & \\
\hline \multicolumn{17}{|c|}{ Stator-reflected high frequency resistance sensitivity $\alpha(1 / \mathrm{k})$} \\
\hline \multicolumn{8}{|c|}{ Pulsating $d$-axis high frequency current $(0.05 \mathrm{pu})$} & \multicolumn{8}{|c|}{ Rotating high frequency current $(0.05 \mathrm{pu})$} & \multirow{2}{*}{ Sensitivity } \\
\hline $\mathrm{fhf}_{\mathrm{hf}}(\mathrm{Hz})$ & $\mathrm{s} / \mathrm{p}$ & Pitch 6 & Pitch 5 & Pitch 4 & Pitch 3 & Pitch 2 & Pitch 1 & $\mathrm{f}_{\mathrm{hf}}(\mathrm{Hz})$ & $\mathrm{s} / \mathrm{p}$ & Pitch 6 & Pitch 5 & Pitch 4 & Pitch 3 & Pitch 2 & Pitch 1 & \\
\hline \multirow{10}{*}{250} & $9 / 6$ & & & & & & 1.441 & \multirow{10}{*}{250} & $9 / 6$ & & & & & & 1.451 & High \\
\hline & $9 / 8$ & & & & & & 0.779 & & $9 / 8$ & & & & & & 0.993 & \\
\hline & $9 / 10$ & & & & & & 0.9815 & & $9 / 10$ & & & & & & 1.219 & \\
\hline & $12 / 10$ & & & & & & 0.684 & & $12 / 10$ & & & & & & 0.768 & \\
\hline & $30 / 10$ & & & & & & 0.037 & & $30 / 10$ & & & & & & 0.089 & \\
\hline & $24 / 16$ & & & & & & 0.045 & & $24 / 16$ & & & & & & 0.298 & \\
\hline & $18 / 6$ & & & & 1.481 & 1.437 & 1.886 & & $18 / 6$ & & & & 1.1591 & 1.304 & 1.404 & \\
\hline & $36 / 6$ & 1.731 & 2.388 & 2.08 & 1.793 & 1.873 & 1.651 & & $36 / 6$ & 1.08 & 1.021 & 1.111 & 1.115 & 0.967 & 0.842 & \\
\hline & $48 / 8$ & 1.563 & 1.532 & 1.422 & 1.255 & 0.864 & 1.035 & & $48 / 8$ & 1.281 & 1.369 & 1.253 & 1.151 & 0.867 & 0.994 & \\
\hline & $60 / 10$ & 1,322 & 1,332 & 1,307 & 1,214 & 0,821 & 0,948 & & $60 / 10$ & 1,112 & 1,186 & 1,098 & 1,010 & 0,989 & 0,948 & Low \\
\hline & $9 / 6$ & & & & & & $\begin{array}{l}1.501 \\
\end{array}$ & & $9 / 6$ & & & & & & $\begin{array}{l}1.548 \\
\end{array}$ & "High \\
\hline & $9 / 8$ & & & & & & 1.053 & & $9 / 8$ & & & & & & 0.822 & \\
\hline & $9 / 10$ & & & & & & 1.241 & & $9 / 10$ & & & & & & 1.054 & \\
\hline & $12 / 10$ & & & & & & 0.808 & & $12 / 10$ & & & & & & 0.717 & \\
\hline 500 & $30 / 10$ & & & & & & 0.132 & 500 & $30 / 10$ & & & & & & 0.063 & \\
\hline 500 & $24 / 16$ & & & & & & 0.112 & 500 & $24 / 16$ & & & & & & 0.057 & \\
\hline & $18 / 6$ & & & & 1.643 & \begin{tabular}{|l|}
1.594 \\
\end{tabular} & 2.049 & & $18 / 6$ & & & & 1.247 & 1.413 & 1.526 & \\
\hline & $36 / 6$ & 1.929 & 2.703 & 2.223 & 1.961 & 2.035 & 1.656 & & $36 / 6$ & \begin{tabular}{|l}
1.357 \\
\end{tabular} & 1.325 & 1.273 & 1.411 & 1.248 & 1.112 & \\
\hline & $48 / 8$ & \begin{tabular}{|l|}
2.047 \\
\end{tabular} & \begin{tabular}{|l|}
2.038 \\
\end{tabular} & 1.942 & 1.87 & \begin{tabular}{|l|}
1.534 \\
\end{tabular} & 1.665 & & $48 / 8$ & \begin{tabular}{|l|}
1.484 \\
\end{tabular} & 1.59 & \begin{tabular}{|l|}
1.479 \\
\end{tabular} & 1.468 & 1.282 & 1.424 & \\
\hline & $60 / 10$ & 1,822 & 1,897 & 1,789 & 1,706 & \begin{tabular}{|l|}
1,664 \\
\end{tabular} & 1,575 & & $60 / 10$ & 1,402 & 1,51 & $\begin{array}{l}1,387 \\
\end{array}$ & 1,349 & 1,256 & 1,297 & Low \\
\hline
\end{tabular}

magnet width. On the other hand, when the flux is driven through 6 teeth, none of them faces the magnet center, of the stator teeth actually face the flux barrier, see Fig.3d-f. This result is an increased sensitivity, as shown in Table IV for $36 / 6$ and 60/10 machine, coil pitch 5; 48/8 machine showing small differences between coil pitches 5 and 6 .

The case of the 18/6 integer slot winding machine can be observed in Fig. 3b. Highest sensitivity is obtained with the lowest coil pitch. The reason for this is that, as for the case of fractional slot machines, the coil pitch 3 arrangement drives the flux generated by the coil though 3 teeth, one of which is facing the magnet center, the other two facing both the magnet and the flux barrier. Coil pitch 1 arrangement, on the contrary, drives all generated flux though the magnet center, increasing therefore the sensitivity of the high frequency resistance to magnet temperature.

The highest sensitivity occurs for the $36 / 6$ configuration (see Fig. 3d). This is because the stator coil center perfectly matches the rotor $d$-axis for all the PMs, maximizing therefore the coupling between the stator high frequency flux and the PM.

Among all 36/6 configurations, pitch 5 provides the best results (see Table IV). The reason for this is that it is the fractional slot machine with the lowest number of poles being evaluated. Coil pitch 5 arrangement provides the highest 


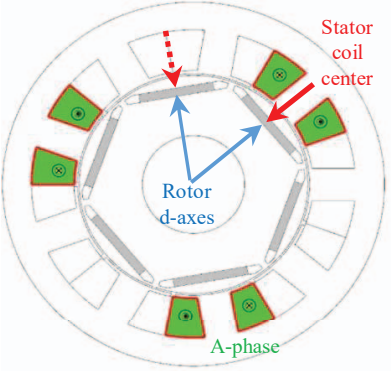

a)

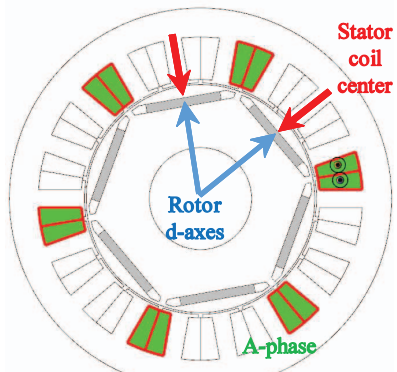

c)

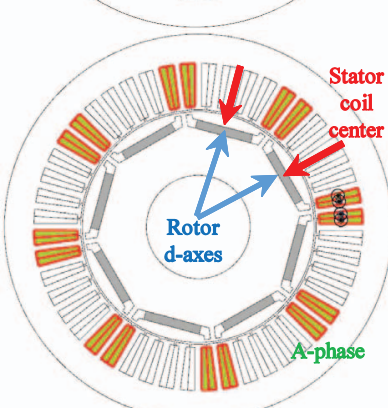

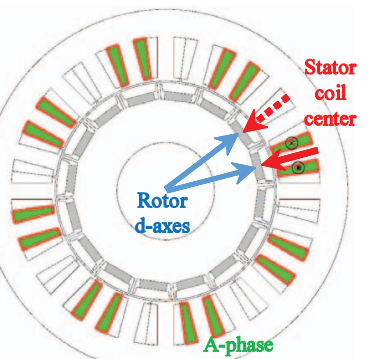

b)
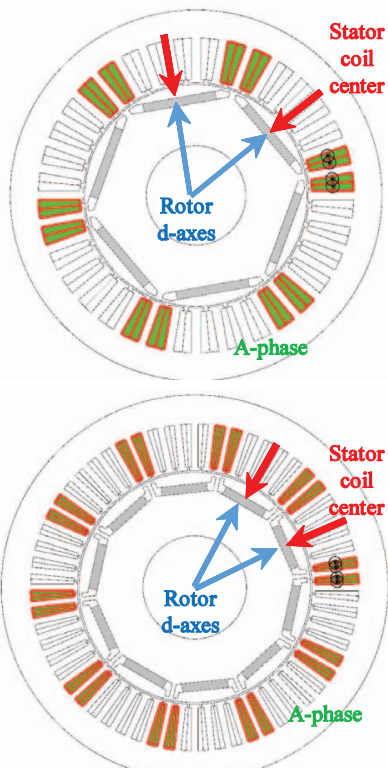
f)

Fig. 3. Cross section of: a) 9/6 IPM machine, b) 24/16 IPM machine, c) 18/6 IPM machine, d) 36/6 IPM machine, e) 48/8 IPM machine and f) 60/10 IPM machine

sensitivity for this machines, due to the position between stator teeth enclosed by one phase coil and the rotor magnets.

If is finally noted that the same trends are observed for the two frequencies that have been evaluated, i.e. $250 \mathrm{~Hz}$ and $500 \mathrm{~Hz}$. Although the sensitivity for the $500 \mathrm{~Hz}$ case is in general higher than for the $250 \mathrm{~Hz}$ case, use the $250 \mathrm{~Hz}$ is considered advantageous, $R_{d h f}$ at $20^{\circ} \mathrm{C}$ is lower at $250 \mathrm{~Hz}$ (see Table IV), meaning that the induced magnet loses are lower too. In addition, as the frequency of the injected signal increases, the weight of the inductive component increases (undesired component) over the resistive component (desired component) in the overall high frequency impedance, see (9) and (14), what might result in a reduction of the accuracy of the method.

It can be also observed from Table IV that for all machines, the sensitivity decreases as the number of poles increase. This is because as the number of poles decreases, the magnet edges are closer to the airgap, the reluctance path being therefore lower in these cases, which results in an increased sensitivity.

Fig 4 shows the magnetic flux density contour of the same machines shown in Fig. 3, no load being applied. The flux density contour are shown for the instant when the pulsating current is maximum in phase a. Fig. 4a corresponds to $9 / 6$ machine (most favorable concentrated winding configuration)

while Fig. 4b corresponds to 24/16 configuration (most unfavorable concentrated winding configuration). It is observed that the 9/6 machine shows higher flux density in the stator tooth that matches the magnet width. The same behavior is observed for flux density in the stator teeth for machines with distributed winding, i.e. Fig. 4c-f. As previously stated, the $30 / 10$ and the $24 / 10$ machines show the lowest sensitivity of $R_{d h f}$ to magnet temperature variations.
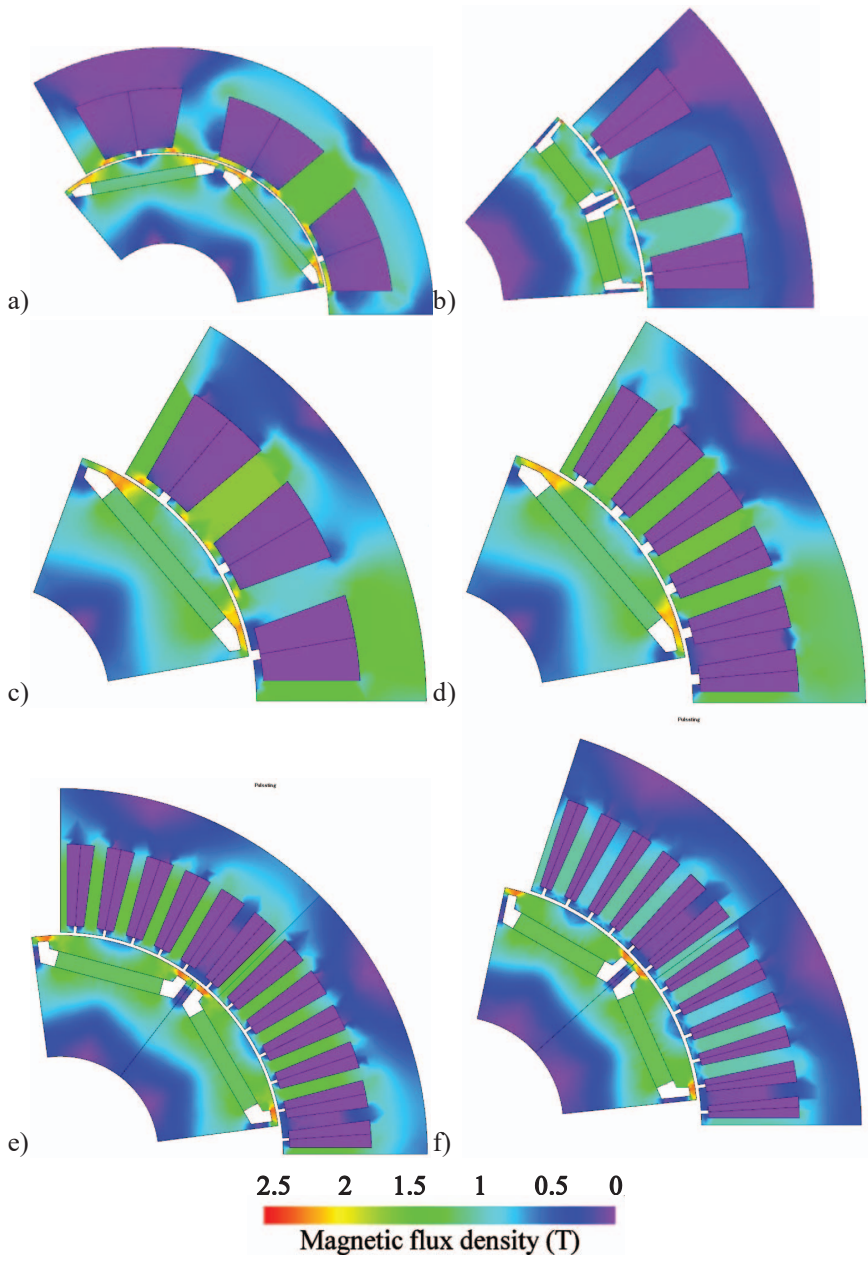

Fig. 4. Contour plot of the magnetic flux density for a) 9/6 IPM machine, b) 24/16 IPM machine , c) 18/6 IPM machine, d) 36/6 IPM machine, e) 48/8 IPM machine and f) 60/10 IPM machine. $I h f=1 \mathrm{~A}(0.05 \mathrm{pu}), I d q=0 \mathrm{~A}$.

\section{CONCLUSION}

This paper presents an analysis of the slots/pole stator winding configuration effect on the sensitivity of high frequency signal injection based magnet temperature estimation methods for PMSM. Different slot/pole combinations been evaluated. The analyzed machines were designed to provide the same torque-speed characteristic and have the same dimensions. Two high frequency injection waveforms and two frequencies have been used, rotating and pulsating. It has been shown that the pulsating injection shows higher sensitivity than the rotating injection and that the 
frequency plays an important role on the sensitivity of high frequency signal injection based temperature estimation based methods. It has been also shown that the slot/pole and pitch configuration affects to $R_{d h f}$ sensitivity to the magnet temperature; the most favorable stator configuration is the $36 / 6$ (pitch 5) for pulsating and the $9 / 6$ for rotating signal injection. Distributed winding machines have higher sensitivities to magnet temperature variation.

\section{REFERENCES}

[1]. T. Sebastian, "Temperature effects on torque production and efficiency of PM motors using NdFeB magnets," IEEE Trans. Ind. Appl., vol. 31, no. 2, pp. 353-357, Mar./Apr. 1995.

[2]. N. Bianchi and T. M. Jahns "Design, analysis, and control of interior PM synchronous machines," Tutorial Course Notes, IEEE-IAS'04, Oct. 2004.

[3]. S. Ruoho, J. Kolehmainen, J. Ikaheimo and A. Arkkio,"Interdependence of demagnetization, loading, and temperature rise in a permanent-magnet synchronous motor," IEEE Trans. Mag., vol. 46, no. 3, pp: 949-953, Mar. 2010.

[4]. D. Reigosa, D. Fernandez, H. Yoshida, T. Kato and F. Briz "Permanen magnet temperature estimation in PMSMs using pulsating high frequency current injection,” . IEEE Trans. on Ind. Appl., vol. 51, no. 4, pp: 3159 - 3168, July-Aug. 2015.

[5]. D. Reigosa, F. Briz, P. García, J. M. Guerrero and M. W. Degner, "Magnet temperature estimation in surface PM machines using high frequency signal injection". IEEE Trans. on Ind. Appl., vol. 46, no. 4, pp: 1468-1475, July-Aug. 2010.

[6]. D. Reigosa, D. Fernandez, T. Tanimoto, T. Kato, F. Briz "Wireless permanent magnet temperature \& field distribution measurement system for IPMSMs," Energy Conversion Congress and Exposition (ECCE), 2015 IEEE, pp. 3996 - 4003, 20-24 Sept. 2015

[7]. C. Kral, A. Haumer and S. B. Lee, "A Practical Thermal Model for the Estimation of Permanent Magnet and Stator Winding Temperatures". IEEE Trans. on Pow. Elect., vol. 29, no. 1, pp: 455-464, Jan. 2014.

[8]. P. Milanfar and J. H.Lang, "Monitoring the Thermal Condition of Permanent-Magnet Synchronous Motors," IEEE Trans. on Aerospace and Electronic Systems, vol. 32, no. 4, pp: 1421-1429, Oct. 1996.

[9]. K. Liu and Z.Q. Zhu "Mechanical Parameter Estimation of Permanent Magnet Synchronous Machines with Aiding from Estimation of Rotor PM Flux Linkage”, IEEE-ECCE, pp.4850-4857, Sept. 2014.

[10]. S. Underwood, and I. Husain, "On-line Parameter Estimation and Adaptive Control of Permanent Magnet Synchronous Machines," IEEE Trans. Ind.Electron., vol. 57, no. 7, pp: 2435-2443, Jun. 2010.

[11].D. Reigosa, D. Fernandez, T. Tanimoto, T. Kato, F. Briz "Permanen Magnet Temperature Distribution Estimation In Pmsms Using BEMF Harmonics," Energy Conversion Congress and Exposition (ECCE), 2015 IEEE , vol., no., pp.768-775, 20-24 Sept. 2015, doi: 10.1109/ECCE.2015.7309767

[12].M. Ganchev, C. Kral, H. Oberguggenberger and T. Wolbank, "Sensorless Rotor Temperature Estimation Of Permanent Magnet Synchronous Motor," IEEE IECON, pp. 2018-2023, Nov. 2011.

[13].D. Reigosa, F. Briz, M. W. Degner, P. García and J. M. Guerrero, "Magnet Temperature Estimation in Surface PM Machines during SixStep Operation”. IEEE Trans. on Ind. Appl., vol. 48, no. 6, pp. 2353 2361, Nov.-Dec. 2012

[14].D. Reigosa, D. Fernandez, T. Tanimoto, T. Kato, F. Briz "Sensitivity Analysis Of High Frequency Signal Injection Based Temperature Estimation Methods To Machine, Assembling Tolerances," Energy Conversion Congress and Exposition (ECCE), 2015 IEEE, vol., no., pp. 6122 - 6129, 20-24 Sept. 2015, doi: 10.1109/ECCE.2015.7310518

[15].J. Choi, Y.Park, S. Jang "Experimental Verification and Electromagnetic Analysis for Performance of Interior PM Motor According to Slot/Pole Number Combination," IEEE Trans. on Magnetics vol. 48, no. 2, pp. 987-990, Feb. 2012.

[16]. I.P. Brown, G.Y. Sizov, L.E. Brown, "Impact of Rotor Design on Interior Permanent-Magnet Machines With Concentrated and Distributed Windings for Signal Injection-Based Sensorless Control and Power Conversion," in Industry Applications, IEEE Transactions on , vol.52, no.1, pp.136-144, Jan.-Feb. 2016, doi: 10.1109/TIA.2015.2464783

[17].Zhu, Z.Q.; Chen, J.T.; Wu, L.J.; Howe, D., "Influence of Stator Asymmetry on Cogging Torque of Permanent Magnet Brushless
Machines," in Magnetics, IEEE Transactions on , vol.44, no.11, pp.3851-3854, Nov. 2008

[18]. D. Fernandez; D. Diaz; J. M. Guerrero; Z. Q. Zhu; F. Briz, "Permanent Magnet Magnetization State Estimation Using High Frequency Signal Injection," in IEEE Transactions on Industry Applications, vol.PP, no.99, pp.1-1. doi: 10.1109/TIA.2016.2541616 